\title{
How does an individual's default behavior on an online peer-to-peer lending platform influence an observer's default intention?
}

\author{
Mingfeng Tang ${ }^{1 *}$ D, Mei Mei ${ }^{2}$, Cuiwen $\mathrm{Li}^{3}$, Xingyang $\mathrm{LV}^{2}$, Xushuang $\mathrm{Li}^{4}$ and Lihao Wang ${ }^{5}$
}

\author{
*Correspondence: tang@swufe.edu. \\ $\mathrm{cn}$ \\ ${ }^{1}$ Sino-French Innovation Research \\ Center, School of Business \\ Administration, Southwestern \\ University of Finance and \\ Economics, No. 55, Guanghua Cun \\ Street, Chengdu 610074, China \\ Full list of author information is \\ available at the end of the article
}

\begin{abstract}
Previous studies indicate that individuals' default behaviors on online peer-to-peer (P2P) lending platforms greatly influence other borrowers' default intentions. However, the mechanism of this impact is not clear. Moreover, there is scarce research in regard to which factors influence the relationship between an individual's default behavior and an observer's default intention. These important questions are yet to be resolved; hence, we conducted two experiments using the scenario-based research method, focusing on Chinese online P2P lending platforms. Our results indicate that an individual's default behavior can trigger an observer's default intention as a result of the imperfect punitive measures as they currently exist on Chinese online P2P lending platforms. Both the observer's moral disengagement level and pragmatic self-activation level serve as mediating variables. In situations where an observer knows an individual's default behavior, the level of intimacy between the defaulter and observer positively affects the relationship between their default behavior and intention. The intimacy level also positively influences the relationship between the individual's default behavior and the two mediator variables. Based on the findings, we provide management suggestions in the context of online P2P lending. Our study sets a foundation for future research to utilize other methods to extend the present research findings to other regions and domains.
\end{abstract}

Keywords: Online P2P lending, Individual default behavior, Observer default intention, Moral disengagement, Pragmatic self-activation

\section{Introduction}

The subprime mortgage crisis that arose from borrowers in the U.S. defaulting on their home loans triggered the global financial crisis. As a result, recently, it has been more difficult for individuals and small businesses to obtain loans from financial institutions (Cao 2009). Online peer-to-peer (P2P) lending has newly emerged in financial markets, providing a convenient way for individuals and small businesses to access financial channels on the Internet. This specific type of financial market allows for borrowers and lenders to directly interact online without banks, other financial institutions, and/ or collateral (Lin et al. 2009; Collier and Hampshire 2010). Online P2P lending platforms facilitate micro credit loan processes across the globe (between persons or

(c) The Author(s). 2020 Open Access This article is licensed under a Creative Commons Attribution 4.0 International License, which permits use, sharing, adaptation, distribution and reproduction in any medium or format, as long as you give appropriate credit to the original author(s) and the source, provide a link to the Creative Commons licence, and indicate if changes were made. The images or other third party material in this article are included in the article's Creative Commons licence, unless indicated otherwise in a credit line to the material. If material is not included in the article's Creative Commons licence and your intended use is not permitted by statutory regulation or exceeds the permitted use, you will need to obtain permission directly from the copyright holder. To view a copy of this licence, visit http://creativecommons.org/licenses/by/4.0/. 
between small firms and persons) (Feng et al. 2017). Trades without collateral and traditional financial intermediates distinguish online P2P lending platforms from traditional financial credit markets (Lee and Lee 2012). However, this difference makes the online P2P lending market inherently risky due to the lack of repayment guarantees and an information asymmetry between borrowers and lenders (Wang et al. 2020). This results in higher default rates in the online P2P lending market in comparison to the traditional financial credit market. Thus, it is necessary to determine which factors influence borrowers' default behaviors. Previous studies have indicated that individuals' default behaviors on online P2P lending platforms greatly influence other borrowers' default intentions. However, there has been a lack of research on the underlying mechanism of this impact.

Online P2P lending platforms originated in the United Kingdom. They have been growing in popularity as a new financial channel since 2005, particularly in the U.S., France, Italy, Canada, China, India, and Turkey. The first Chinese P2P online lending platform - PPDai- emerged in 2007 in Shanghai. It uses internet information technology to offer online lending trades to micro borrowers and lenders. PPDai has become a leading online consumer finance platform in China, connecting underserved individual borrowers with financial institutions. A number of additional online P2P lending platforms have since been created (e.g., Creditease, My089, and Edai365). These platforms are registered from the first tier cities (Beijing, Shanghai, and Guangzhou) to the second and third tier cities (in Mainland China). The volume of online lending transactions increased from millions of RMB to 96.49 billion RMB in 2019, and PPDai continues to grow at a rapid pace. In its first year and half, there were more than 80 , 000 registered PPDai users. By 2012, the accumulated online trade volume of PPDai was 344 million RMB, with 195 million of the total transactions occuring in 2012 (Ding 2012; Wu 2013).

Creditease established offices in Beijing in 2006 and other 14 cities in a three-year period, raised billions of funds from thousands of lenders, and became a nationwide online P2P lending platform. By the end of 2016, there were 2448 such platforms in China, with a transaction value of 2063.872 billion RMB. In 2016, these platforms experienced a $110 \%$ growth compared to the previous year (WDZJ and YINGCANZIXUN 2017). Despite their exponential growth, these platforms have been plagued by high default rates, which limits their further growth and development. The Chinese Online P2P Lending Industry White Book (2013) highlighted that the average default rate on these platforms across 29 provinces was $6.45 \%$, with some provinces having default rates greater than $10 \%$. This is much higher than the default rate in traditional financial institutions. Given the prevalence and negative consequences of default behaviors on P2P platforms, it is important to understand how and when borrowers engage in these behaviors.

Previous studies have mainly focused on identifying the factors that affect the behaviors of borrowers and lenders. On the borrower side, hard information factors such as sex (Barasinska 2009), age, race, physiological features (Sydnor and Pope 2009; Pope and Sydnor 2011), loan size, borrower financial situations (Collier and Hampshire 2010), credit scores, credit card use, and borrower records (Lin et al. 2009; Lin 2009; Serrano-Cinca et al. 2015) influence whether the person will default on a loan. A number of soft information factors such as social networks (Lin et al. 2009; Lin 2009), affiliation with reliable communities (Lopez 2009; Lopez et al. 2009) and social capital (Greiner and Wang 2009; 
Lin 2012; Zhang et al. 2017) also influence the success rate of a loan, the loan interest rate, and default behavior. In regard to the lender side, there have been a few studies on certain investor behaviors such as herding (Herzenstein et al. 2011).

However, the existing literature mainly focuses on online P2P platforms in the US (e.g., Prosper) and has largely neglected such platforms in developing countries like China. Scholars have used P2P platform data in China to study the impact of platform information on online P2P lending transactions and borrower/lender behavior (Wang et al. 2020) and to test whether investor attention affects the return in online lending environments (He et al. 2020). While P2P scholars have made significant efforts to examine the determinants of default behaviors in P2P lending, the existing research has primarily focused on borrower defaults. Therefore, little attention has been paid to the interactions between actual borrowers and observers in P2P lending. Observers in our study refers to individuals who fit the characteristics of online P2P lending borrowers and who have knowledge of the default behaviors of the borrowers.

To decrease online P2P lending defaults, most Chinese online P2P lending platforms maintain a black list, which discloses defaulters' personal information such as names, contact details, and identification number. With this black list, the platforms endeavor to warn other borrowers and prevent their potential default behaviors. However, this list may inadvertently trigger the observers to follow the defaulters' behaviors. This could be attributed to a "monkey see, monkey do" phenomenon, which researchers have found holds true in social situations (Lu et al. 2012). Although this phenomenon has received increasing research attention, the existing studies have largely failed to offer a systematic theoretical framework to specify the underlying mechanisms in regard to how observers' default intentions are influenced by online P2P lending defaulters. Our study aims to address these unresolved questions through two carefully designed scenario experiments. Based on the theory of planned behavior (TPB), we explore what variables play a role in the relationship between individual default behaviors and observer default intentions.

The structure of the paper is organized as follows. The next section reviews the existing research on online P2P lending default behavior, such the measurements of online P2P lending defaults and the predictors of loan default behavior. Then, relevant research hypotheses and a theoretical research framework are proposed. The third section details the two experiments that were conducted in the current study, presenting the subjects, study designs, procedures, and results. The fourth section draws conclusions from the study findings, including theoretical and practical implications, limitations, and future research directions.

\section{Literature review and research hypotheses}

\section{Measurement of online P2P lending default}

The existing literature on the default of P2P borrowers can be categorized into three streams. The first category defines default as a failure to make the required payment for a specific period. Some scholars define default as a failure to make the required payment for over 2 months (Lin 2009; Lin et al. 2009; Lin 2012; Lu et al. 2012), while others define it as a failure to make the required payment for over 30 days (SerranoCinca et al. 2015), or even over 4 months (Freedman and Jin 2010). The second 
category focuses on the severity of default and defines it as a failure to make the required payment for different lengths of overdue time. For example, the default of individuals who do not make the required payment for over 5 months is coded as 0 ; for those with overdue payments for more than 4 months and less than 5 months, the default is coded as 1; for those with overdue payments for less than 4 months, the default is coded as 2 (Greiner and Wang 2009). The third category defines default as a failure to make the required payment and interest for a specific time (Chen et al. 2016).

The definition used depends on the scholar's research target and purpose. Because our study aims to understand the observer's default intention at PPDai (which was recently renamed the FinVolution Group), we adopt the default definition given by Lu et al. (2012). However, we modify the overdue time from over 60 days to over 90 days in line with the financial industry in China, which views default as a failure to make the required payment for over 90 days. In the case of PPDai, when borrowers do not make the required payment for over 90 days, the platform provides the borrowers' information to the lenders to facilitate legal action. It also provides legal counseling to lenders, if so requested (Lu et al. 2012). This is the highest level of default policy on PPDai, and it is applied when the borrowers are capable of paying before the due date but choose not to pay. In other words, such borrowers have intentionally defaulted on the loan.

\section{Predictors of loan default behavior}

There are two levels of factors (i.e., the personal and interpersonal levels) that can influence the borrower's default behavior. In regard to the personal-level factors, the existing literature on online P2P lending platforms mainly focuses on three kinds of factors that influence an individual's default behavior, namely, hard information, soft information, and cheap talk of borrowers (Freedman and Jin 2010). As mentioned previously, hard information refers to factual information that can be shared objectively, such as sex (Barasinska 2009), age, race, physiological features (Sydnor and Pope 2009; Pope and Sydnor 2011), loan size, borrower financial situations (Collier and Hampshire 2010), credit scores, income, and assets (Emekter et al. 2015; Lin 2009; Serrano-Cinca et al. 2015). Previous research established that an individual's credit score has a negative relationship with his or her default behavior (Emekter et al. 2015; Freedman and Jin 2010; Krumme and HerreroLopez 2009; Lin et al. 2009; Serrano-Cinca et al. 2015); in fact, credit score is the most significant factor influencing an individual's default behavior (Serrano-Cinca et al. 2015).

Scholars have recently argued that combining other hard information such as a borrower's income, assets, and other debt with the borrower's credit score may worsen the individual's default behavior (Serrano-Cinca et al. 2015; Emekter et al. 2015). Although hard information provided by online P2P lending platforms has a negative relationship with the borrower's behavior, this factor cannot solely predict the borrower's likelihood of defaulting. Adding soft information to a model that predicts borrowers' default behaviors may be helpful to lower the default rate (Freedman and Jin 2010; Zhang et al. 2016).

Soft information refers to a borrower's social network information (Lin 2009). Given that default behavior can damage one's social reputation, P2P lending scholars have argued that borrowers' social capital has a negative relationship with their default behavior (Freedman and Jin 2010; Lin 2012; Zhang et al. 2016). Particularly in the Chinese social context where the social credit score evaluation system is not well developed, soft 
information is more powerful than hard information in situations where lenders use information to predict borrowers' default behaviors (Zhang et al. 2016). Scholars have also discussed how the borrower's social capital index influences the loan success, interest, and default rates. By including the structural index (size of borrower's social group) and relational index (whether the social group has lender members, whether inner group lenders lend money to inner group borrowers, whether group members' personal identities can be verified in real life, and whether the group leader guarantees inner borrower's debt), scholars have demonstrated that the group leader's guarantee for an inner borrower's debt has a positive relationship with the borrower's default behavior (Lin 2009, 2012; Chen et al. 2016).

Cheap talk is the last type of personal information (Freedman and Jin 2010). It includes the loan's characteristics as well as the borrower's personal statistics. Scholars usually add cheap talk information to the borrower default prediction model (hard and soft information are the two main factors of the model) to improve the model's forecast accuracy. In regard to loan characteristics, studies have found that business loans are associated with the highest default rate, whereas marriage loans are associated with the lowest default rate (Serrano-Cinca et al. 2015). Further, scholars have found that loan amount has a negative relationship with the borrower's default behavior (Kumar 2007). High initial rates are accompanied by higher default rates (Everett 2010). Short-term loans are associated with higher default rates than are long-term loans because longterm loans have a lower payment per session (Lu et al. 2012).

Although research on the personal-level factors influencing loan default behavior has been carried out for a long time, and even though scholars have reached certain agreements, few studies have been conducted on the interpersonal factors that influence default behavior. Recently, however, a few scholars have focused on these interpersonal effects; for example, Lu et al. (2012) extracted secondary data from PPDai to test the interpersonal interactions between P2P borrowers and found that the "monkey see, monkey do" phenomenon does exist on Chinese online P2P lending platforms. Their research provides evidence that a black list can actually provide negative examples of defaulted loans for observers to mimic.

As P2P lending is a relatively new financial alternative, there is a lack of research on the antecedents and consequences of its financing mechanism (Bruton et al. 2014). In particular, the research on how online P2P lending default behaviors influence observer default intentions remains underdeveloped. Moreover, little is known about which factors mediate the relationship between an individual's default behavior and an observer's default intention, and there is a lack of research on determining whether an intimate connection can affect this relationship. China is a collective culture-based society and interpersonal relationships play an extremely important role in this society. Therefore, our research in regard to the influence of an individual's default behavior on an observer's default intention is relevant in China owing to this societal context. In other words, this culture makes it easier for the observer to follow the demonstrator's example (Qiu et al. 2003). Thus, research on interpersonal influencing factors, such as how individual default behavior influences an observer's default intention, has a great application value. To further explore how and when an observer's default intention is influenced by a P2P lending individual's default behavior, the present study aims to examine which variables influence the relationship between individual default behavior and observer default intention. 


\section{Main effect and mediating effect hypotheses}

The TPB is likely the most widely used theory for illustrating how intentions are formed (Heath and Gifford 2002; Rivis and Sheeran 2003; Sánchez-Medina et al. 2014). Behavioral intention refers to an individual's subjective probability to engage in that behavior (Fishbein and Ajzen 1975). According to the TPB (Ajzen 1991), the three main factors influencing an individual's intention are attitude, subjective norm, and perceived behavior control. Attitude refers to an individual's general feeling of favorableness toward performing a behavior. Subjective norm is the influence of family members, friends, and others who are close to the individual and can change the individual's opinions in regard to performing or not performing the behavior. Perceived behavioral control refers to the individual's perceived ease or difficulty of performing the behavior (Carpenter and Reimers 2005).

The existing literature shows that the TPB is suitable for predicting unethical behavioral intentions. For example, Carpenter and Reimers (2005) applied the TPB to predict a manager's propensity to commit fraud in financial reporting decisions. Their research finding confirms that the TPB accurately forecasts whether managers' decisions are ethical or unethical. Scholars have also found evidence that the TPB can accurately predict whether college students will cheat (Hsiao and Yang 2011), and that it can be used to describe behavioral intentions in regard to using pirated software (Kwong and Lee 2002; Lin et al. 1999; Peace et al. 2003).

In the Chinese online P2P lending context, the newly emerging financial market is in its early stages and is facing several challenges (e.g., the lack of a specific supervision agency, a low market entry threshold, and numerous platforms of varying quality) (Feng et al. 2017). Individuals are more likely to have favorable attitudes toward defaulting, be influenced by other defaulters' behaviors, and perceive defaulting to be easy due to the imperfect credit system, information asymmetry, and the lack of an influential third party credit institution Thus, we argue that individuals tend to default when they are exposed to other borrowers' default behaviors. As abovementioned, there is empirical evidence that observers' default behaviors may be influenced by other borrowers' defaults in P2P lending (Lu et al. 2012). Following this research stream, we propose the following hypothesis:

H1: An individual's default behavior promotes observers' default intentions

Bandura introduced the theory of moral disengagement (Moore et al. 2012), which attempts to explain how one's self-regulatory process can fail when the moral disengagement mechanisms disable the cognitive links between the transgressive behavior and the self-sanctioning that should prevent it (Bandura 1986; Bandura 1990). Moral disengagement enables a person to decrease his/her moral responsibility and allows him/her to be exempt from self-punishment (Detert et al. 2008). An individual's moral disengagement changes along with the environment (Ashforth and Anand 2003). Feeling a sense of belonging to inner group members is an important aspect of an observer's personal environment, with an inner group referring to a subgroup that consists of the inner group members. This is because a group leader will implicitly categorize group members as an "inner" or "outer." Inner group members have a closer connection to the leader. Their behaviors are heavily influenced by the leader, and they are more likely to behave like the leader in comparison to the outer group members. When inner group individuals conduct immoral behaviors, an observer's moral disengagement will increase and he/she can find an excuse to reinterpret his/her own 
immoral behavior when he/she wants to engage in similar immoral behaviors. Trevino (1986) showed that when observing colleagues' unethical behaviors, the observer intended to engage in the same unethical behavior. Ashforth and Anand (2003) also found that upon witnessing corruption behavior, observers may believe that the behavior is reasonable and imitate their counterpart's observed corruption behavior.

There are many clues that indicate whether other individuals can be classified into one's inner group. For example, individuals whose names are similar, whose birthdays are the same day, and even whose hobbies are the same will result in them accepting each other as inner group members (Tajfel 1982; Pelham et al. 2005). For online P2P lending, individual defaulters and observers are all borrowers with the same identity. In this regard, the observer may take defaulters as his/her inner group members. Thus, the observer's default intention may heighten as a result of being influenced by the surrounding inner group interpersonal environment. Indeed, scholars have studied the relationship between moral disengagement and unethical behavior and found that moral disengagement can decrease an individual's moral sensation (Moore 2008), and that it can lead to additional unethical behaviors such as attacking others and engaging in insulting, academic fraud, corruption, and aggressive behaviors (Aquino et al. 2007; Paciello et al. 2008; Yang et al. 2013). Thus, we propose the second hypothesis below:

H2: Moral disengagement is the mediating variable between an individual's default behavior and an observer's default intention

Like other mental representations, the meaning of self-concept is different according to different circumstances (Bargh 1990; Kruglanski 1996). Kivetz and Tyler (2007) categorized self-concept into two types: pragmatic self and idealistic self. The idealistic self places values and principles above practical considerations; therefore, it is more closely related to the person's sense of true self. The pragmatic self focuses on situational opportunities and constraints for the purpose of action guidance. Since money has a natural relationship with business, when priming the money concept, individuals' decisions are more likely to be influenced by the business decision framework (Kouchaki et al. 2013). It also means that individuals will present a more rational and personal character. An individual will make decisions based on a calculation of the benefits. Such characteristics also show that the individual's pragmatic self is active. Activation of the pragmatic self is very important for an individual to form his/her motivation (Cantor et al. 1986). Such emphasis on specific situations and benefit calculations may result in individuals neglecting their moral principles and chasing certain instrumental benefits (Deci and Ryan 1985), such as money, goods, and other material resources (Kassar and Ryan 1993). Thus, we propose the following hypothesis:

H3: Level of pragmatic self-activation is the mediation variable between an individual's default behavior and an observer's default intention

\section{The role of an intimate connection between individual defaulter and observer}

According to the TPB (Ajzen 1991), subjective norm refers to one's perceived support from the people surrounding him/her, which could influence his/her decision in regard to conducting a certain behavior. Demonstration norm is one kind of subjective norm. Ajzen (2006) argued that an individual will feel more supported and influenced by the opinions of the people surrounding him/her if such an individual values those people. 
Thus, we argue that an intimate connection, which implies a sense of trust, deep understanding, and thorough emotional foundation (Li et al. 2015), will help to shape an individual's intention. In the P2P lending context, a demonstration norm may affect an individual's default intention via interactions with the surrounding people. Specifically, for the observer, the individual defaulter will be more important to the observer if the two individuals have an intimate relationship. In addition, this relationship will then result in the observer being influenced to conduct similar default behaviors. Thus, we propose the fourth hypothesis below:

H4: In a situation where an observer knows the defaulter's behavior, an intimate connection between an individual defaulter and observer will positively affect the observer's default intention.

As above mentioned, an individual's moral disengagement changes based on the corresponding environment (Ashforth and Anand 2003). An inner group individual's behavior is the observer's important personal environment. The observer's moral disengagement will increase when he/she observes an inner group individual's unethical behavior (Ashforth and Anand 2003; Trevino 1986). In the online P2P lending context, observers view themselves as members of a borrower group. Their moral disengagement is more likely affected by inner group borrowers. However, it is necessary to discuss whether an observer's moral disengagement will differ based on varying intimacy levels between defaulter and observer.

The vicarious self-perception theory proposed by Goldstein and Cialdini (2007) enlightens our research. This theory systematically illustrates how another person's behavior can indirectly change an observer's attitudes and behaviors. Vicarious selfperception theory holds that individuals who are personally connected can have overlapping mental representations (Aron and Aron 1986). Therefore, an individual may blur the boundary between himself/herself and others, taking some of the others' characteristics and feelings into his/her cognitive and emotional system. When such a phenomenon happens, the vicarious self-perception phenomenon happens at the same time. Individuals will take others' behaviors as their own and will judge their own behavior based on others' behaviors. Recent research has shown that the vicarious selfperception phenomena can happen very easily. In fact, even subtle connections (such as similar names, same birthdays, being in the same group, etc.) can lead to the vicarious self-perception phenomenon occurring (Cialdini and De Nicholas 1989; Gino and Galinsky 2012; Pelham et al. 2005).

In the same vein, the observers and defaulters in online P2P lending are all borrowers and share the same identity. When observing others' default behaviors, the vicarious self-perception phenomenon is very likely to happen. An observer may feel that he/she can also default when observing others' default behaviors. Such a feeling contradicts an observer's internalized moral standards (Aquino and Reed 2002). Contradictions between cognition and behavior will lead to cognitive dissonance (Goodnow et al. 1958). Cognitive dissonance theory proposes two methods to solving the dissonance: changing the attitude or changing the behavior. In the present research, the observer cannot change his/her behavior because he/she did not conduct the default behavior. Therefore, changing one's attitude is the only choice.

This approach to changing one's moral judgment to decrease the inner moral contradiction is in line with moral disengagement. According to the vicarious self-perception 
theory, when observing individual default behavior, the observer's moral disengagement level will increase. Moreover, the specific degree to which moral disengagement occurs is determined by the degree of shared identity between the individual defaulter and observer. Intimacy is often identified with closeness (e.g., Helgeson et al. 1987), and closeness has generally been categorized by different types of relationships such as a friend or parent versus a stranger (Aron et al. 1992). Most definitions of intimacy sharply focus on the central idea of sharing one's innermost thoughts and feelings with others (McAdams 1988). A higher level of intimacy means that there is a closer interpersonal connection, and that each individual feels that his/her innermost self has been validated, understood, and cared for by the other (Reis and Shaver 1988). Intimacy allows for individuals to easily form a shared identity, and the vicarious self-perception phenomenon is more likely to occur when there is an intimate connection. Thus, we propose our fifth hypothesis below:

H5: In a situation where an observer knows the defaulter's behavior, an intimate connection between individual defaulter and observer will positively affect the observer's moral disengagement level.

Most researchers view the self-concept term to be multi-dimensional and dynamic (Markus and Wurf 1987). Like other mental representations, an individual's self-concept varies since humans are influenced by their social environments (Bargh 1990; Kruglanski 1996). As mentioned above, when the concept of money is primed, the observer's pragmatic self will be activated.

According to construal level theory, a high level of interpretation is associated with attention to moral standards, while a low level of interpretation is associated with attention to situational benefits. This is because a high level of interpretation results in individuals keeping a distance between themselves and a certain event. Staying distant helps individuals to better consider the essential moral attributes of the event. This is characteristic of an individual's idealistic self. On the contrary, a low level of interpretation leads to individuals sinking into the details of certain events and calculating the costs/benefits. An individual will pay more attention to the situational benefits than to moral principles (which should be insisted on). This is characteristic of the pragmatic self. Many researchers support this argument (Eyal et al. 2006; Fujita et al. 2006; Kivetz and Tyler 2007).

Therefore, in the online P2P lending context, it is easy to deduce that when there is an intimate relationship between an individual who defaulted and an observer, the social distance between the two is small and, subsequently, the observer will use a low level of interpretation to comprehend and possibly mimic the default behavior. Hence, we propose the sixth hypothesis below:

H6: In a situation where an observer knows the defaulter's behavior, an intimate connection between the individual who defaulted and the observer will positively affect the level to which the observer's pragmatic self is activated.

We synthesize the above six hypotheses in our theoretical research framework (see Fig. 1).

\section{Study 1}

Study 1 aimed to test the main effect of individual default behavior on an observer's default intention and the mediating effects of moral disengagement and pragmatic selfactivation level. 


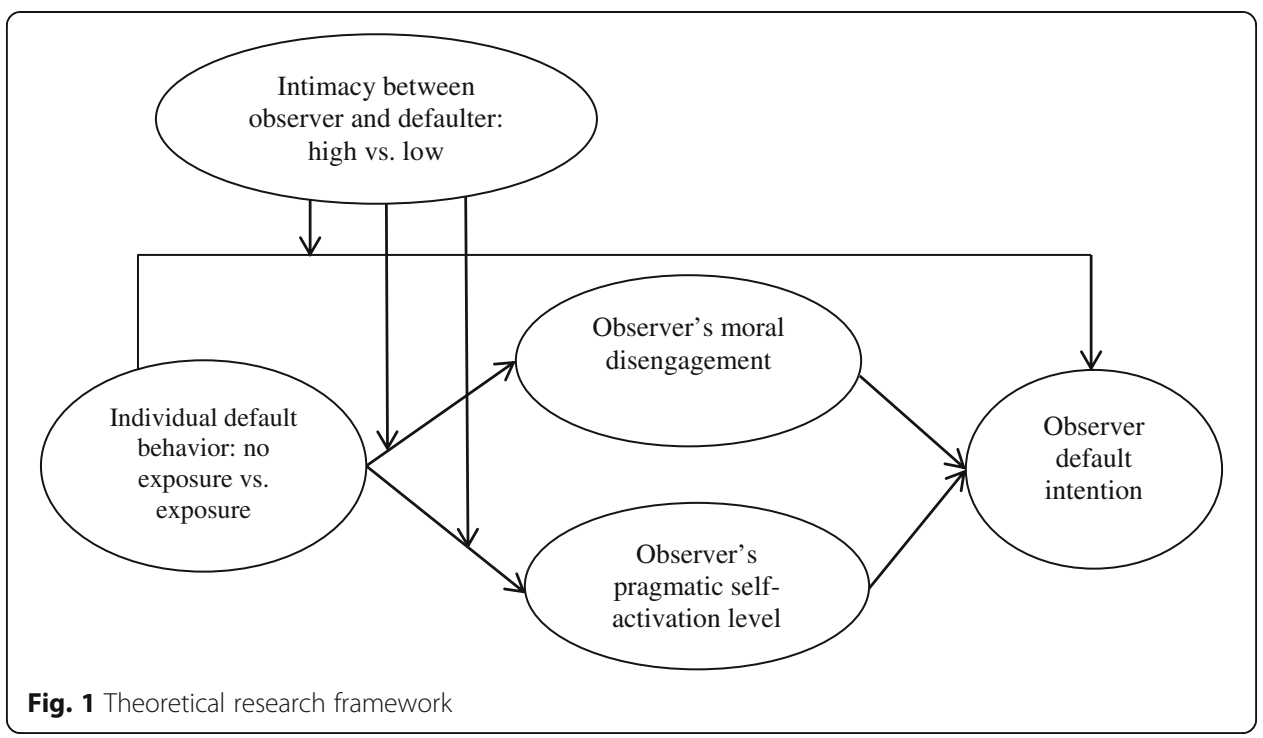

\section{Subjects and design}

A single-factor between subjects design (individual default behavior: exposure to other people's default vs. no exposure to other people's default) was conducted in study 1 . In order to ensure that the selected subjects reflected the true characteristics of online P2P lending borrowers, we interviewed a PPDai executive in Shanghai on May 22, 2015. We asked the manager about general information about the borrowers and PPDai's online lending operations. Based on the acquired information from the interviewed manager and the 2015 Annual Report of Online P2P Lending Industry released by Wangdaizhijia, ${ }^{1}$ we learned that personal consumption dominates online lending (regardless of the person's sex). Borrowers are industry workers, service employees, office employees, small business entrepreneurs (e.g., Taobao sellers), students, or others who need money within 2 years. Therefore, we randomly sampled a number of entrepreneurs, employees, college students, and others who matched the above characteristics of real online P2P borrowers. According to the demographic information, we made sure that all the participants have similar characteristics with real P2P borrowers. Furthermore, in order to exclude the influence of borrowing experience, we also required that the chosen participants should have no P2P borrowing experience in the study.

To test whether the subjects understood and were engaged in the experimental situation, we asked the subjects the following question: "which statements best summarize the given scenario?" Subjects who answered the question incorrectly were excluded from the final analysis. We removed five invalid questionnaires that were incomplete. A total of 120 individuals participated in this experiment (55.8\% females, $\mathrm{M}_{\mathrm{age}}=32.6$ years). There were 60 participants in each of the experimental and control groups, which were randomly formed.

${ }^{1}$ https://www.wdzj.com/news/baogao/25661.html; Wangdaizhijia is the most influential web portals of P2P online lending platforms in China. 


\section{Procedure}

First, we provided an online P2P lending scenario to the subjects. In order to make the scenario reflect a real online P2P lending situation, a simulated online P2P website was designed, which refers to Haokuaidai website (www.cdkuaidai.com), and studies one and two were conducted on this simulated website. The perceived default behavior of others was measured with this material. Given that this study involved ethical judgments, using first person ("I") in the scenario settings may have caused moral approval problems, and it would have been difficult to obtain the participants' true attitudes. To avoid this problem, some scholars use "someone/somebody" to replace "I" (Zhuang et al. 2009). In our study, we adopted Zhuang et al.'s (2009) method and used the third person "Li Ming" instead of "I." Here, Li Ming represented an online P2P borrower. Below is the situation description provided to the no exposure group:

"Recently, a HaoKuaidai online P2P lending platform was founded. In order to promote its business, HaoKuaidai provides online borrowers with a short-term noninterest loan service. The loan interest will be paid by HaoKuaidai. Li Ming is interested in the service and borrows RMB10000 from HaoKuaidai."

"Note: Defaulters who delay the required payment by more than 90 days will have their personal information exposed on the HaoKuaidai platform (only on the HaoKuaidai platform), such as name, telephone number, and identification card number; the credit rating of the defaulter will drop to the lowest possible score on the HaoKuaidai platform. Lenders reserve the right to appeal to the court. If the lenders prosecute the default, the penalty interest rate can be as high as 70/10000. For example, the penalty interest of RMB10000 over 90 days reaches RMB 6300."

In contrast, the exposure experimental group was shown the following information after disclosing the above mentioned punishment information: "When the repayment day was approaching, Li Ming unintentionally browsed the list of defaulters (individuals who did not make the required payment for more than 90 days) and saw their personal information, which is exposed online by HaoKuaidai. He also found that none of the defaulters had been prosecuted by the lenders. Aside from their personal information being exposed to the public, the defaulters suffered no other loss at all." At the end of this part, we used two questions for attention check: How many days of delayed payment will lead to the punishment of defaulter's personal information exposure? How much will the penalty interest of RMB10000 be if the borrower delays to pay the loan over 90 days? For realism checking, we asked the subjects about the realism evaluation of the website information, and excluded subjects whose actual perception score is relatively lower.

In the second part of the study, we measured the observer's default intention and the two mediator effects. In order to ensure the effectiveness of the participants' responses, we emphasized to the subjects that they should put themselves in the role of Li Ming and answer with their own real ideas and judgments. The subjects were also assured that there was no right or wrong answer and that all of the responses would be kept confidential. We adopted Tang and Liu's scale (2012) to measure the observer's default intention by asking the respondents how likely it was that Li Ming would delay 
repayment by more than 90 days. We adapted seven items from a scale developed by Moore (2008) to measure the observers' moral disengagement. In addition, Kivetz and Tyler's scale (2007) was used to measure the observers' pragmatic self-activation levels. The same response scale was used for all measures, which was a seven-point scale, ranging from 1 ("very unlikely") to 7 ("very likely"). Finally, all subjects were required to provide demographic information (gender, age) and respond as to whether or not they have had experience with credit default.

\section{Results of study 1}

For the no exposure group, the average default intention was significantly lower than the exposure group $\left(\mathrm{M}_{\text {no exposure }}=2.03, \mathrm{M}_{\text {exposure }}=3.13, \mathrm{t}=4.92 ; p<0.001\right)$, indicating that an individual's default behavior can increase an observer's default intention. Thus, $\mathrm{H} 1$ is supported. For the no exposure group, the average moral disengagement was significantly lower than the exposure group $\left(\mathrm{M}_{\mathrm{no}}\right.$ exposurel $=2.18, \mathrm{M}_{\text {exposure }}=3.04, \mathrm{t}=-$ 5.89; $p<0.001$ ), thus supporting $\mathrm{H} 2$. In addition, the average pragmatic self-activation level for the no exposure group was significantly lower than the exposure group $\left(\mathrm{M}_{\mathrm{no}}\right.$ exposurell $=2.55, \mathrm{M}_{\text {exposure }}=3.72, \mathrm{t}=-5.61 ; p<0.001$ ). Therefore, $\mathrm{H} 3$ is supported.

To further confirm the mediating effects, we conducted a bias-corrected bootstrapping analysis using a PROCESS software developed by Hayes (2013). The results of the PROCESS analysis (Model 4, 5000 samples) confirmed that the indirect effects of an individual's default behavior on an observer's default intention via the observer's moral disengagement (indirect effect $=0.828$, boot $\mathrm{se}=0.138,95 \% \mathrm{CI}=[0.556,1.099]$ ) and pragmatic self-activation level (indirect effect $=0.427$, boot $\mathrm{se}=0.094,95 \% \mathrm{CI}=[0.256$, 0.623]) were both significant. In addition, the PROCESS results indicated that an individual's default behavior has a significant direct effect on an observer's default intention (effect $=0.823$, boot se $=0.134,95 \% \mathrm{CI}=[0.559,1.087])$, suggesting that the observer's moral disengagement and pragmatic self-activation level play partial mediating roles. Therefore, $\mathrm{H} 2$ and $\mathrm{H} 3$ were further supported.

Study 1 tested the main effect and mediating effect hypotheses. The results showed that individuals who are exposed to other people's defaults in P2P lending are more likely to produce default intentions. Therefore, this provides evidence that the "monkey see, monkey do" phenomenon does exist in the online P2P lending context. Furthermore, our bootstrapping results showed that an observer's moral disengagement and pragmatic self-activation level have partial mediating effects on the relationship between individual default behavior and the observer's default intention. Study 2 aimed to add to the findings of study 1 by examining when this phenomenon is more likely to happen.

\section{Study 2}

The aim of study 2 was to test the effect of an intimate relationship on an observer's intention to default.

\section{Subjects and design}

In study 2, it is only under the condition that the observers had seen other individuals' default behaviors that the "exposure to other people's defaults $\times$ intimacy" group can 
exist. Therefore, we conducted a one-factor (intimacy degree between observer and defaulter: high versus low) between-subjects design. We included 120 individuals who matched the true characteristics of actual online P2P borrowers in our scenario-based experiments ( $56.7 \%$ females, $M_{\text {age }}=29.6$ years). We formed the experimental and control groups randomly, with 60 subjects in each group.

\section{Procedure}

In the experimental scenario, to tap into the subjects' perceptions of the interpersonal intimate connection between the borrower and defaulter, we first used a pictorial measure that was developed by Aron et al. (1992). For the high intimacy group, we showed two largely overlapping circles (see Fig. 2, left picture). Below the circles, we added a note to explain that one circle represents the self and the other represents another person, and that the overlapping part indicates the intimate connection between the two individuals.

To the low intimacy group, we presented two separate circles on a whiteboard (see Fig. 2, right picture). Below the circles, we added a note to explain that one circle represents the self and the other represents another person, whereas the overlapping part indicates the intimate connection between the two individuals. Thus, the separated circles represent a situation where there is not an intimate connection between the two individuals.

Next, both the high and low intimacy groups were required to write down the name of the person who reminded him/her of the intimate connection he/she observed in the picture. The subjects were also asked to write down the exact relationship between themselves and this person. The high intimacy group often responded that the person was their sibling, parent, child, or grandparent. The low intimacy group always responded that the person was a stranger. Then, each subject used the seven-point Likert scale to rate the degree of felt intimacy.

Next, we provided the same online P2P lending scenario as the one used in study 1 except that the individual default information was disclosed to both the high and low intimacy groups. The following scenario was provided: "When repayment day was approaching, Li Ming unintentionally browsed the list of defaulters (who delayed paying back the borrowed money for more than 90 days) and saw their personal information, which is exposed online by HaoKuaidai. From the disclosed information, Li Ming can identify that he has a certain intimate relationship with one of the defaulters (the degree of intimacy is the same as shown in Fig. 2). In addition, none of the defaulters were prosecuted by the lenders. Except for their personal information being exposed to the public, the defaulters suffered no other loss at all."

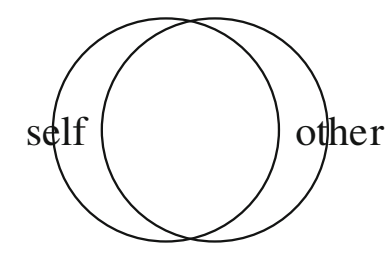

High-intimate connection

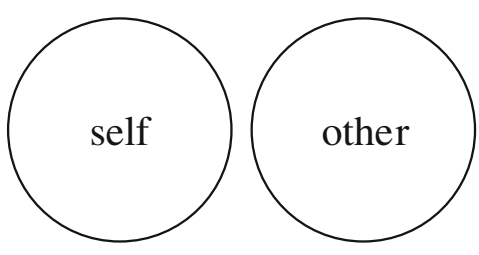

Low-intimate connection

Fig. 2 Scale for measuring the intimate connection between borrower and defaulter 
The attention check and realism check questions remained the same as those in study 1. And we measured the observer's default intention, the observers' moral disengagement and pragmatic self-activation levels by using the seven-point Likert scale. Finally, all subjects were required to provide demographic information (gender, age).

\section{Results of study 2}

The results of the intimacy manipulation check showed that the high intimacy group's intimacy score was significantly higher than that of the low intimacy group $\left(\mathrm{M}_{\text {high }}=\right.$ $4.88, \mathrm{M}_{\text {low }}=2.20, \mathrm{t}=16.70, p<0.001$ ), suggesting that the manipulation was successful. We then verified the effect of an intimate connection on the observer's default intention. The results showed that the average observer's default intention in the high intimacy group was significantly higher than that in the low intimacy group ( $\mathrm{M}_{\text {high }}=$ 4.93, $\mathrm{M}_{\text {low }}=3.70, \mathrm{t}=5.211, p<0.001$ ). Thus, $\mathrm{H} 4$ is verified, which means that the observers will have higher default intentions when they perceive a more intimate relationship with the individual who defaulted.

We also verified the effect of intimacy on the observer's moral disengagement. We found that the observer's moral disengagement in the high intimacy group was significantly higher than that in the low intimacy group $\left(\mathrm{M}_{\text {high }}=4.18, \mathrm{M}_{\mathrm{low}}=3.73, \mathrm{t}=2.059\right.$, $p<0.05)$. Thus, $\mathrm{H} 5$ is verified, which means that the observers will have a higher level of moral disengagement when they perceive a more intimate relationship with the individual who defaulted.

Along the same lines, we verified the effect of intimacy on the observer's pragmatic self-activation level. We found that the observer's pragmatic self-activation level in the high intimacy group was significantly higher than that in the low intimacy group $\left(\mathrm{M}_{\text {high }}=5.07, \mathrm{M}_{\text {low }}=4.33, \mathrm{t}=2.640, p<0.01\right)$. Thus, $\mathrm{H} 6$ is verified, which means that the observers will have a higher pragmatic self-activation level when they perceive a more intimate relationship with the individual who defaulted.

To further confirm the effect of the level of an intimate connection between observer and defaulter on the observer's default intention, we conducted a bias-corrected bootstrapping analysis with the PROCESS procedure. The results confirmed that interpersonal closeness does indirectly affect an observer's default intention via an observer's moral disengagement (indirect effect $=0.095$, boot se $=0.040,95 \% \mathrm{CI}=[0.029,0.186]$ ) and pragmatic self-activation level (indirect effect $=0.142$, boot se $=0.049,95 \% \mathrm{CI}=$ $[0.052,0.246])$. In addition, the bootstrapping results indicate that the level of intimate connection between observer and defaulter has a significant direct effect on the observer's default intention (effect $=0.352$, boot se $=0.050,95 \% \mathrm{CI}=[0.253,0.451]$, This suggests that there is a partial mediating effect between an intimate connection and an observer's default intention.

Study 2 tested the effect of an intimate connection on the observer's default intention. The results showed that an intimate relationship between the observer and the defaulted borrower will affect the observer's moral disengagement, pragmatic selfactivation level, and default intention. The observer's default intention is stronger when he/she has a closer relationship with the defaulter. These findings, together with the results of study 1, indicate the existence of certain boundary conditions for the "monkey see, monkey do" phenomenon in online P2P lending. 


\section{Conclusion}

To decrease the number of borrowers who default, many Chinese online P2P lending platforms publish a black list to warn other borrowers against committing similar defaults. However, the black list may actually provide observers with negative examples. Given the prevalence of the "monkey see, monkey do" phenomenon in social situations (Robinson and O'Leary-Kelly 1998), our research used the scenario-based experiment method to determine how individuals' default behaviors can increase observers' default intentions. Study 1 found that the observers' moral disengagement and pragmatic selfactivation levels mediate the relationship between individual default behaviors and observer default intentions. Study 2 confirmed that an intimate connection between defaulters and observers positively affects the following: the relationship between behavior and intention, the relationship between an individual's default behavior and the observer's disengagement level, as well as the relationship between an individual's default behavior and the observer's pragmatic self-activation level.

\section{Theoretical implications}

Our research makes three theoretical contributions. First, it enriches the existing literature regarding the factors influencing online P2P lending default behavior. Recent related research focuses on hard and soft information; however, little research has been conducted on the interpersonal influencing factor. China is a collective cultureoriented society, and interpersonal relationships play a very important role in guiding people's behavior. We tested the mediating role of an observer's moral disengagement and pragmatic self-activation level and the effect of an intimate connection between defaulting individuals and observers on the relationship between individuals' default behaviors and observers' default intentions. The confirmed effects allowed us to conclude that individual default behavior can increase the observer's default intention.

Second, our study extends the applicability of the "monkey see, monkey do" phenomenon to online P2P lending platforms. Jones and Ryan (1998) pointed out that an individual's unethical behavior does not occur in a vacuum. As an important social phenomenon, the "monkey see, monkey do" phenomenon has been analyzed by many scholars. Some scholars have studied this phenomenon in the company management context, as well as in exam-cheating and game-task contexts (McCabe et al. 2002; O'Fallon and Butterfield 2011). However, the "monkey see, monkey do" phenomenon in online P2P lending platforms is a new social situation that needs further research, and our study helps to fill the existing gap. By testing whether an intimate connection between defaulters and observers positively affects the relationship between behavior and intention, our research verifies the existence of the above phenomenon on Chinese online P2P lending platforms.

Third, this study builds a more solid theoretical foundation for "monkey see, monkey do" phenomenon research. Even though the research relating to the "monkey see, monkey do" phenomenon has been viewed as an important topic, there is no solid theoretical framework to explain the phenomenon (O'Fallon and Butterfield 2011). Our research adopts several theories (theory of planned behavior, construal level theory, and vicarious self-perception) to build an integrative theoretical model to conduct a deep analysis of the "monkey see, monkey do" phenomenon. 


\section{Practical implications}

Our work also makes a number of practical contributions. Our research addresses whether a black list of defaulting individuals is an effective way to decrease the default rate on online P2P lending platforms in China. All the experiment designs are based on the real default management regulations of Chinese online P2P lending platforms. Our research results show that the black list is not an effective punitive method to decrease the default rate. On the contrary, it has a negative example effect on the observer's default intention. It is necessary that further research be conducted to learn how to avoid this negative effect of a black list.

According to our test results regarding the two mediating variables, individual default behavior can raise an observer's moral disengagement level and pragmatic self-activation level. For the first mediating variable, we propose that Chinese online P2P lending platforms promote positive moral information, such as showcasing conscientious borrowers, to decrease observers' moral disengagement levels. As for the second mediating variable, there are two ways to decrease the observer's pragmatic self-activation level. The first is to transform the observer's thinking framework into a business decision framework. Previous studies have confirmed that time conception priming can change an individual's ways of thinking, as it lets an individual focus on issues that are more important than money, such as moral principles and personal feelings (Mogilner 2010). Therefore, time conception priming can decrease an individual's pragmatic self-activation level and decrease the negative influence of individual default behavior. The second way is to decrease the benefits of defaulting. If there are few consequences to defaulting, it is difficult for the observer to activate his/her pragmatic selfactivation level. It would therefore be useful if the disclosure content of black lists were changed.

Most Chinese online P2P lending platforms only disclose the information of defaulters who have not been prosecuted by law. This gives observers the impression that if they default, there will be no punishment at all except for personal information exposure, which can lead to economic loss. If Chinese online P2P lending platforms only publish the information of defaulters who have been prosecuted by law, observers will overestimate the default cost. At the same time, the default benefit will decrease in tandem with the observer's pragmatic self-activation level. Increasing the default punishment severity is also effective as it raises the default cost directly. The default benefit will decrease and the observer's pragmatic selfactivation level will decrease.

In China, there has been proliferation of small online P2P lending platforms; however, they do not share the borrowers' credit information with each other. The credit loss to defaulters remains almost negligible, as they can register on other platforms and borrow money there very easily. Hence, accelerating social credit score information sharing would be a good measure to decrease the observer's pragmatic self-activation level and decrease his/her default intention. Moreover, we suggest that Chinese online P2P platforms collect the credit information of borrowers' social networks, which would be helpful in identifying other potential defaulters. Even though the online P2P lending industry continuously grows in a healthy way, there is still the substantial challenge of borrowers defaulting. 


\section{Limitations and future research directions}

Considering the lack of research on online P2P lending default intention, our study sheds light on how online borrowers' default behavior influences observers' default intentions. Despite its strengths, the present study has several limitations. First, the generalizability of the research findings is limited because of the small sample size. Existing studies have shown that a small sample size below 200 is sufficient to conduct scenario-based experiment research and for a path analysis (e.g., Duan et al. 2016; Shen et al. 2016; Roche et al. 2016; Huang et al. 2018; Shuqair et al. 2019). In light of the recommendations of 10 subjects for each observation variable (Huang 2004), our sample sizes are adequate for testing our hypotheses. However, future research should recruit more samples and extend the research findings to other regions and domains. Second, as we used the self-report survey method in the two studies, it is possible that there were common method biases (Podsakoff et al. 2003). We suggest that future research use multisource data to examine the results. Third, although the participants we recruited do match the actual borrowers' characteristics in the online P2P market, these participants had no P2P lending experience. To improve the study's external validity, we encourage future researchers to use real borrowers to replicate our findings. Last, the present study examined observers' default intentions as a dependent variable. Although this adds important information to our understanding of the ripple effect of default in P2P lending, to dig deeper into the "monkey see, monkey do" phenomenon, further research may explore observers' default behaviors as triggered by other defaulters.

Abbreviations

P2P: Peer-to-peer; TPB: Theory of planned behavior

\section{Acknowledgements}

We would like to acknowledge the financial support provided by Southwestern University of Finance and Economics (grand number JBK2002028), National Natural Science Foundation of China (grant numbers G0302/71403221;

71764026) as well as Sichuan Science and Technology Bureau (grand number 2017ZRO240).

\section{Authors' contributions}

This work was conducted in collaboration with all authors. Conceptualization: M.F.T.; literature review: M.F.T., C.W.L., X.S.L., L.H.W.; methodology and data analysis: M.F.T., M.M., C.W.L., X.Y.L.; Original draft writing: M.F.T., M.M.; Review and editing: M.F.T., M.M.; Project administration and funding acquisition: M.F.T. All authors read and approved the paper.

Funding

This study was financed by Southwestern University of Finance and Economics (grand number JBK2002028), National Natural Science Foundation of China (grant numbers G0302/71403221; 71764026) and Sichuan Science and Technology Bureau (grand number 2017ZR0240).

Availability of data and materials

Source of data sets are available from the authors on reasonable request.

Competing interests

The authors declare that they have no competing interests.

\section{Author details}

${ }^{1}$ Sino-French Innovation Research Center, School of Business Administration, Southwestern University of Finance and Economics, No. 55, Guanghua Cun Street, Chengdu 610074, China. ${ }^{2}$ School of Business Administration, Southwestern University of Finance and Economics, Chengdu, China. ${ }^{3}$ Haerbin University of Science and Technology Rongcheng Campus, Rongcheng, China. ${ }^{4}$ School of Economics, Zhejiang University, Hangzhou, China. ${ }^{5}$ Syracuse University, Syracuse, USA.

Received: 31 July 2019 Accepted: 18 August 2020

Published online: 30 September 2020

References

Ajzen I (1991) The theory of planned behaviour. Organ Behav Hum Dec 50(2):179-211 
Ajzen I (2006) Constructing a theory of planned behavior questionnaire. Unpublished Manuscr Retrieved 7:861-871 Aquino K, Reed A (2002) The self-importance of moral identity. J Pers Soc Psychol 83:1423-1440

Aquino K, Reed A, Thau S, Dan F (2007) A grotesque and dark beauty: how moral identity and mechanisms of moral disengagement influence cognitive and emotional reactions to war. J Exp Soc Psychol 43(3):385-392

Aron A, Aron EN (1986) Love and the expansion of self: understanding attraction and satisfaction. Contemp Sociol 17(2):268269

Aron A, Aron NE, Smollan D (1992) Inclusion of other in the self scale and the structure of interpersonal closeness. J Pers Soc Psychol 63(4):596-612

Ashforth BE, Anand V (2003) The normalization of corruption in organizations. Res Organ Behav 25(19):1-52

Bandura A (1986) Social foundations of thought and action: A social cognitive theory. Prentice-Hall, Englewood Cliffs

Bandura A (1990) Mechanisms of moral disengagement. In: Reich W (ed) Origins of terrorism: psychologies, ideologies, states of mind. Cambridge University Press, Cambridge

Barasinska N (2009) The role of gender in lending business: evidence from an online market for peer-to-peer lending. In: Working Paper, FINESS

Bargh JA (1990) Goal and intent: goal-directed thought and behavior are often unintentional. Psychol Inq 1:248-251

Bruton G, Khavul S, Siegel D, Wright M (2014) New financial alternatives in seeding entrepreneurship: Microfinance, crowdfunding, and peer-to-peer innovations. Entrepreneurship Theory Pract 39(1):9-26

Cantor N, Markus HR, Niedenthal P, Nurius P (1986) On motivation and the self-concept. In: Sorrentino RM, Higgins ET (eds) Handbook of motivation and cognition: foundations of social behavior. Guilford Press, New York

Cao FQ (2009) The implications of global financial crisis on China. Int Financ 5:3-6

Carpenter TD, Reimers JL (2005) Unethical and fraudulent financial reporting: applying the theory of planned behavior. J Bus Ethics 60(2):115-129

Chen XR, Zhou LN, Wan DF (2016) Group social capital and lending outcomes in the financial credit market: An empirical study of online peer-to-peer lending. Electron Commerce Res Appl 15:1-13

Cialdini RB, De Nicholas ME (1989) Self-presentation by association. J Pers Soc Psychol 57(4):626-631

Collier B, Hampshire R (2010) Sending mixed signals: Multilevel reputation effects in Peer-to-Peer lending markets. In: Proceedings of the 2010 ACM conference on computer supported cooperate work. CSCW 2010, Savannah

Deci EL, Ryan RM (1985) Intrinsic motivation and self-determination in human behavior: perspectives in social psychology. Plenum Publishing Co., New York

Detert JR, Treviño LK, Sweitzer VL (2008) Moral disengagement in ethical decision making: a study of antecedents and outcomes. J Appl Psychol 93(2):374-391

Ding J (2012) Research on P2P lending platform and online borrowers - the case of PPDai.com. In: Master dissertation, SWUFE

Duan J, Sun J, Jian D, Tian X (2016) The influence of entrepreneurial attribute framing on entrepreneurial intention: an entrepreneurial cognition perspective. Nankai Bus Rev 19(5):182-192

Emekter R, Tu Y, Jirasakuldech B, Lu M (2015) Evaluating credit risk and loan performance in online peer-to-peer (P2P) lending. Appl Econ 47(1):54-70

Everett, CR (2010) Group membership, relationship banking and loan default risk: The case of online social lending. Pepperdine University Working Paper. Available at SSRN: http://ssrn.com/abstract=1114428.

Eyal T, Liberman N, Sagristano MD, Trope Y (2006) Resolving value conflicts in planning the future. In: Tel Aviv University working paper

Feng B, Ye Q, Chen D (2017) Review on P2P online lending and new research opportunities for China's case. J Manage Sci China 20(4):113-126

Fishbein M, Ajzen I (1975) Belief, attitude, intention, and behavior: an introduction to theory and research. Addison Wesley, Reading

Freedman S, Jin GZ (2010) Does social network solve ienformation problems for peer-to-peer lending? Evidence from prosper.com. In: NET Institute Working Paper

Fujita K, Trope Y, Liberman N, Levin-Sagi M (2006) Construal levels and self-control. J Pers Soc Psychol 90(3):351-367

Gino F, Galinsky AD (2012) Vicarious dishonesty: when psychological closeness creates distance from one's moral compass. Org Behav Hum Dec 119(1):15-26

Goldstein NJ, Cialdini RB (2007) The spyglass self: a model of vicarious self-perception. J Pers Soc Psychol 92(3):402

Goodnow J, Bruner JS, Festinger L (1958) A theory of cognitive dissonance. Stanford University Press, Stanford

Greiner ME, Wang H (2009) The role of social capital in people-to-people lending marketplaces. In: ICIS 2009 Proceedings

Hayes AF (2013) Introduction to mediation, moderation, and conditional process analysis: a regression-based approach. Guilford Press, New York

He F, Qin SQ, Zhang XT (2020) Investor attention and platform interest rate in Chinese peer-to-peer lending market. Financ Res Lett. https://doi.org/10.1016/j.frl.2020.101559

Heath Y, Gifford R (2002) Extending the theory of planned behavior: predicting the use of public transportation. J Appl Soc Psychol 32(10):2154-2189

Helgeson VS, Shaver P, Dyer M (1987) Prototypes of intimacy and distance in same-sex and opposite-sex relationships. J Soci Pers Relationships 4:195-233

Herzenstein M, Dholakia UM, Andrews RL (2011) Strategic herding behavior in peer-to-peer loan auctions. J Interact Mark 25(1):27-36

Hsiao CH, Yang C (2011) The intellectual development of the technology acceptance model: a co-citation analysis. Int J Inf Manag 31(2):128-136

Huang F (2004) Theory and application of structural equation model. Wunan, Taibei

Huang IX, Dong P, Zhang M (2018) Crush on you: romantic crushes increase consumers' preferences for strong sensory stimuli. J Consum Res 46(1):1-15

Jones MT, Ryan VL (1998) The effect of organizational forces on individual morality: Judgment, moral approbation, and behavior. Bus Ethics Q 8(3):431-445

Kassar T, Ryan RM (1993) A dark side of the American dream correlates of financial success as a central life aspiration. J Pers Soc Psychol 65:410-422 
Kivetz Y, Tyler TR (2007) Tomorrow I'll be me: the effect of time perspective on the activation of idealistic versus pragmatic selves. Org Behav Hum Dec 102(2):193-211

Kouchaki M, Smith-Crowe K, Brief AP, Sousa C (2013) Seeing green: mere exposure to money triggers a business decision frame and unethical outcomes. Org Behav Hum Dec 121(1):53-61

Kruglanski AW (1996) Goals as knowledge structures. In: Gollwitzer PM, Bargh JA (eds) The psychology of action: linking cognition and motivation to behavior. Guilford Press, New York

Krumme K, Herrero-Lopez S (2009) Do lenders make optimal decisions in a peer-to-peer network? In: Proceedings of the IEEE/WIC/ACM international joint conference on web intelligence and intelligent agent technology

Kumar, S (2007) Bank of One: Empirical Analysis of Peer-to-peer Financial Marketplaces. Proceedings of the 2007 Americas Conference on Information Systems Paper 305.

Kwong TCH, Lee MKO (2002) Behavioral intention model for the exchange mode internet music piracy. In: Proceedings of the 35th Hawaii international conference on system sciences

Lee E, Lee B (2012) Herding behavior in online P2P lending: an empirical investigation. Electron Commer R A 11(5):495-503

Li R, Li Y, Zhang X (2015) The effects of tie strength and relationship asymmetry on the willingness to forgive. Finance Econ 5:97-109

Lin MF (2009) Peer-to-peer lending: An empirical study. In: AMCIS 2009 Doctoral Consortium

Lin MF (2012) Judging borrowers by the company they keep: friendship networks and information asymmetry in online peer-to-peer. Manag Sci 9:1-19

Lin MF, Prabhala NR, Viswanathan S (2009) Social networks as signaling mechanisms: evidence from online peer-to-peer lending. In: Working Paper, University of Maryland

Lin T-C, Hsu MH, Kuo FY, Sun PC (1999) An intention model-based study of software piracy. In: Proceedings of the 32nd Hawaii international conference on system sciences

Lopez SH (2009) Social interactions in P2P lending. In: Working Paper, MIT

Lopez SH, Pao ASY, Bhattacharrya R (2009) The effects of social interactions on P2P lending. In: Working Paper, MAS Final Project

Lu Y, Bin G, Ye Q, Sheng Z (2012) Social influence and defaults in P2P lending networks. In: Thirty Third International Conferences on Information Systems, Orlando

Markus H, Wurf E (1987) The dynamic self-concept: a social psychology perspective. Annu Rev Psychol 38(41):407-421

McAdams DP (1988) Personal needs and personal relationships. In: Duck S (ed) Handbook of personal relationships: Theory, research and interventions. Wiley, New York, pp 7-22

McCabe DL, Treviño LK, Butterfield KD (2002) Honor codes and other contextual influences on academic integrity: A replication and extension to modified code settings. Res High Educ 43(3):357-378

Mogilner C (2010) The pursuit of happiness: time, money, and social connection. Psychol Sci 21(1):1348-1354

Moore C (2008) Moral disengagement in processes of organizational corruption. J Bus Ethics 80(1):129-139

Moore C, Detert RJ, Trevino KL, Baker LV, Maye MD (2012) Why employees do bad things: Moral disengagement and unethical organizational behavior. Pers Psychol 65:1-48

O'Fallon MJ, Butterfield KD (2011) Moral differentiation: Exploring boundaries of the "Monkey See, Monkey Do" perspective. J Bus Ethics 102(3):379-399

Paciello M, Fida R, Tramontano C, Lupinetti C, Caprara GV (2008) Stability and change of moral disengagement and its impact on aggression and violence in late adolescence. Child Dev 79(5):1288-1309

Peace AG, Galletta DF, Thong JYL (2003) Software piracy in the workplace: a model and empirical test. J Manag Inf Syst 20(1): 153-177

Pelham BW, Carvallo M, Jones JT (2005) Implicit egotism. Curr Dir Psychol Sci 14(2):106-110

Podsakoff PM, MacKenzie SB, Lee JY, Podsakoff NP (2003) Common method biases in behavioral research: a critical review of the literature and recommended remedies. J Appl Psychol 88(5):879-903

Pope DG, Sydnor JR (2011) What's in a picture? Evidence of discrimination from prosper.com. J Hum Resour 45(1):53-92

Qiu B, Chen SJ, Sun SQ (2003) Cultural differences in E-commerce: a comparison between the U.S. and China. J Glob Inf Manag 11(2):48-55

Reis HT, Shaver P (1988) Intimacy as interpersonal process. In: Duck S (ed) Handbook of personal relationships: Theory, research and interventions. Wiley, New York, pp 367-389

Rivis A, Sheeran P (2003) Descriptive norms as an additional predictor in the theory of planned behaviour: a meta-analysis. Curr Psychol 22(3):218-233

Robinson SL, O'Leary-Kelly AM (1998) Monkey see, monkey do: The influence of work groups on the antisocial behavior of employees. Acad Manage J 41(6):658-672

Roche KM, Daskalova P, Brown DS (2016) Anticipated multiple role management in emerging Adults: A test of the social cognitive career selfmanagement model. J Career Asses:1-14

Sánchez-Medina AJ, Romeroquintero L, Sosacabrera S (2014) Environmental management in small and medium-sized companies: an analysis from the perspective of the theory of planned behavior. PLoS One 9(2):e88504

Serrano-Cinca C, Gutiérrez-Nieto B, López-Palacios L (2015) Determinants of default in P2P lending. PLoS One 10(10):139-142

Shen H, Zhang M, Krishna A (2016) Computer interfaces and the "direct-touch" effect: can iPads increase the choice of hedonic food? J Mar Res 53(5):745-758

Shuqair S, Pintoa CD, Mattilab SA (2019) Benefits of authenticity: post-failure loyalty in the sharing economy. Ann Tour Res 78:102741

Sydnor JR, Pope DG (2009) What's a picture? Evidence of discriminations of loan fundability in the prosper.com marketplace. In: Working Paper, papers.ssin.com

Tajfel H (1982) Experimental studies of intergroup behavior. Cognitive Anal Soc Behav 13:227-246

Tang TLP, Liu H (2012) Love of money and unethical behavior intention: Does an authentic supervisor's personal integrity and character (ASPIRE) make a difference? J Bus Ethics 107(3):295-312

Trevino LK (1986) Ethical decision making in organizations: a person-situation interactions model. Acad Manag Rev 11(3):601_617

Wang Q, Xiong X, Zheng ZX (2020) Platform characteristics and online peer-to-peer lending: evidence from China. Financ Res Lett. https://doi.org/10.1016/j.frl.2020.101511 
WDZJ, YINGCANZIXUN (2017) 2016 China Online P2P Lending Industry Annual Report. https:/www.wdzj.com/news/ yanjiu/52614.html

Wu XL (2013) Analysis on the status quo and supervision methods of online peer-to-peer lending in China. S China Financ 439:43-47

Yang Q, Wu X, Zhou X, Vohs KD, Mead NL, Baumeister RF (2013) Diverging effects of clean versus dirty money on attitudes, values, and interpersonal behavior. J Pers Soc Psychol 104(3):473-489

Zhang C, Lu T, Xu Y (2017) Assessment of borrowers' delinquency and default behaviors in online P2P lending: a two-stage model. In: Proceedings from the 21st Pacific Asia conference on information systems (PACIS)

Zhang Y, Jia H, Diao Y, Hai M, Li H (2016) Research on credit scoring by fusing social media information in online peer-topeer lending. Procedia Comput Sci 91:168-174

Zhuang GJ, Zhou YL, Peng Q (2009) Experimental effect of moral training towards gray marketing. Nankai Bus Rev 12(6):101110

\section{Publisher's Note}

Springer Nature remains neutral with regard to jurisdictional claims in published maps and institutional affiliations.

Submit your manuscript to a SpringerOpen ${ }^{\circ}$ journal and benefit from:

- Convenient online submission

- Rigorous peer review

- Open access: articles freely available online

High visibility within the field

- Retaining the copyright to your article

Submit your next manuscript at $\boldsymbol{\nabla}$ springeropen.com 